\title{
Glioma cell proliferation is inhibited by miR-342-3p, miR-377/E2F1 signaling pathway
}

\author{
H. YING*, C. CHI \\ The Fourth Affiliated Hospital of Harbin Medical University, Harbin, Heilongjiang Province, China \\ *Correspondence: 2835037671@qq.com
}

Received August 5, 2018 / Accepted January 8, 2019

\begin{abstract}
In recent years, microRNAs (miRNAs) have been reported to be critical regulators to influence tumor genesis or its further progression by directly targeting downstream tumor related genes in glioma. However, there are still many underlying mechanisms related to miRNAs signaling pathway that remain to be uncovered. In the present study, we found that miR-342-3p and miR-377 inhibited the glioma cell line proliferation and arrested the cell cycle at G1 phase. Inhibition of miR-342-3p and miR-377 function promoted the cell proliferation. miR-342-3p and miR-377 target the E2F1 3'UTR to repress its expression on both mRNA and protein level. Downregulation of E2F1 inhibited the cell proliferation and arrested the cell cycle. Overexpression of E2F1 blocked the proliferation repression caused by miR-342-3p or miR-377 in glioma cells. This study showed the function of miR-342-3p, miR-377/E2F1 axis in regulating glioma cells proliferation and provided the potential therapeutic target.
\end{abstract}

Key words: glioma cell, proliferation, cell cycle, miRNAs, E2F1

Malignant glioma is one of the most common center nervous system tumors worldwide. Glioma showed the rapid cell proliferation and lower apoptotic rate [1-3]. Although there is a remarkable development of clinical treatments, the glioma patients still show poor prognosis $[4,5]$. Investigation of the molecular signaling that regulates the glioma cell proliferation will uncover the potential regulatory pathway and therapeutic targets in future.

MicroRNAs (miRNAs), endogenous short noncoding RNAs, have been reported to regulate many physiological processes including embryonic development, disease occurrence, ageing, and so on [6-10]. miRNAs also play important role in regulating tumor genesis and development. miR-132 suppresses the breast cancer proliferation by targeting Foxa1 [11]. miR-503 repressed cell proliferation and invasion in osteosarcoma [12]. In glioma cells, miRNA-485-5p repressed proliferation and invasion by targeting TPD52L2 [13]. Downregulation of miR-377 promotes proliferation and migration in oral squamous cells [14]. miR-377 also inhibits the cell proliferation in pancreatic cancer [15]. Additionally, miR-324 may be a diagnostic biomarker, treatment target and also relates to the survival rate in esophageal cancer [16]. However, more miRNAs regulating signaling pathway that can modulate the cell proliferation remain unclear in glioma.
E2F1, a member of the E2F family transcription factors, has been reported to play critical role in regulating cell cycle and apoptosis $[17,18]$. In epithelial ovarian cancer, E2F1 regulates $\ln$ cRNA RAD51 antisense RNA 1 to promote cell cycle progression and repress apoptosis. The level of E2F1 is closely related to the poor prognosis [19]. Transcription of E2F1 also can be upregulated by ANKRD22 to promote the cell proliferation [20]. Downregulation of E2F1 by miR-320 inhibits the glioma cell proliferation [21]. miR-98 targets E2F1 to increase chemosensitivity in leukemia cells [22]. It is of importance to investigate the upstream regulator of E2F1, especially miRNAs, to determine the critical miRNA-E2F1 pathway regulating glioma cell proliferation.

Here we found that both miR-342-3p and miR-377 significantly inhibited the cell proliferation of glioma cell lines U251 and U87. Inhibition of miR-342-3p or miR-377 promoted the proliferation. We also detected that G1 phase of the cell cycle was regulated by these miRNAs. We further found that both of miR-342-3p and miR-377 targeted the 3'UTR of E2F1 and downregulated the E2F1 expression. Downregulation of E2F1 in glioma cells inhibits the proliferation and arrests the cell cycle. Rescue experiments also confirmed that overexpression of E2F1 restored the proliferation repression caused by miR-342-3p or miR-377. This study indicated the 
function of miR-342-3p/miR-377/E2F1 signaling pathway in regulating the cell cycle and proliferation in glioma cells, which also uncovered the potential function of this pathway for further clinical treatment.

\section{Materials and methods}

Cell culture. Human glioma cancer cell lines U251 and U87 cells were cultured in DMEM medium (Hyclone, Logan, UT) with $10 \%(\mathrm{v} / \mathrm{v})$ fetal bovine serum (FBS) (Gibco, USA), at $37^{\circ} \mathrm{C}, 5 \% \mathrm{CO}_{2}$ atmosphere, supplemented with $100 \mathrm{U} / \mathrm{ml}$ penicillin and $100 \mu \mathrm{g} / \mathrm{ml}$ streptomycin sulfate (Sigma, USA).

Transfection of miRNAs. We transiently transfected 40 pmol miRNA-342-5p, miR-377 miRNA mimics or miRNA inhibitors (Ribobio, China) by using Lipofectamine 2000 (Thermo, USA) into the glioma cancer cell line for miRNAs overexpression or functional inhibition respectively.

qRT-PCR. M-MLV Reverse Transcriptase kit (Takara, China) was used for producing cDNA from total RNA isolated by Rnaiso Plus (Takara). qRT-PCR included 40 cycles of amplification by SYBR Green qPCR Mix (Takara). Level of genes was normalized against GAPDH $\left(2^{-\Delta \Delta C t}\right)$. Primer sequences are as follows: GAPDH (forward: 5'-CTGGGCTACACTGAGCACC-3'; reverse: 5'-AAGTGGTCGTTGAGGGCAATG-3'), E2F1 (forward: 5'-CATCCCAGGAGGTCACTTCTG-3'; reverse: 5'-GACAACAGCGGTTCTTGCTC-3'), Cyclin E (forward: 5'-CGCCTGCCGGGACTGGAG-3'; reverse: 5'-TCTTCCTGGAGCGAGCCG-3'), Cyclin D (forward: 5'-GACCACCGAGGAGTTTAATCG-3'; reverse: 5'-GGGTGATCCCCTGATCCTTTG-3'), p21 (forward: 5'-TGTCCGTCAGAACCCATGC-3'; reverse: 5'-AAAGTCGAAGTTCCATCGCTC-3'), p27 (forward: 5'-TAATTGGGGCTCCGGCTAACT-3'; reverse: 5'-TGCAGGTCGCTTCCTTATTCC-3').

Western blot. SDS buffer (Beyotime, China) was used to obtain cell proteins for further electrophoresis. Then the proteins were transferred onto PVDF membranes (Whatman, USA) and detected by antibodies listed as follows: E2F1 (ab14768, Abcam, USA), GAPDH (ab97626, Abcam). Levels of protein signals were detected by Chemistar ECL Western Blotting Substrate (Thermo).

Plasmid construction. E2F1 3'UTR was cloned from U251 cell DNA by PCR. The sequences of primers are as follows: PF: 5'-GGCGTCGACGCCAGAGAGCCACCGCCG-3' (Sal1 restriction enzyme); PR: 5'-GGCTCTAGAGCCCTGGCTCTGCCCCTG-3' (Xbal restriction enzyme). The sequence was inserted into the pGL3cM vector (Promega).

Knockdown of E2F1. The sequences of siRNA of E2F1 are as follows: siRNA-1 of E2F1: 5'AUGCUACGAAGG UCCUGACACGUCA-3'; siRNA-2 of E2F1: 5'-AAAGUUCUCCGAAGAGUCCACGGCU-3'.

Overexpression of E2F1. The total RNA was isolated by using RNAiso Plus (Takara, China) from the U251 cells and used for cDNA synthesizing using the Takara-PrimeScript RT reagent Kit (Takara). The fragment of CDS of E2F1 was amplified by following primers and inserted into the overex- pression vector Fugw: PF: 5'-GGCGGATCCATGGCCTTGGCCGGG-3' (BamH1 site), PR: 5'-GGCGAATTCGAGTGGGGGGACCTAAAGACT-3'(EcoR1 site).

Cell proliferation analysis. U251 and U87 cells at the density of $1.2 \times 10^{4}$ cells per well were seeded into 96 -well plates. MTS proliferation assay was performed by Cell Titer 96 AQueous One Solution Cell Proliferation Assay (Promega).

Cell counting. In order to detect the total cell number in different treatment groups, we cultured the cells in 6-well culture dishes. For cell counting, we prepared the cell suspensions digested by trypsine (Gibco, USA). Then number of cells per milliliter was detected by using Countstar cell count meter (Inno-Alliance Biotech, USA) to determine the total cell number in each group.

Luciferase reporter assays. U251 cells at a density of $3 \times 10^{4}$ cells per well were seeded into 48 -well plates. Cells were co-transfected with $200 \mathrm{ng}$ of the UTR luciferase reporter, $4 \mathrm{ng}$ Renilla vector, and 25 pmol miRNA mimics (Ribobio) by Lipofectamine 2000 (Thermo, USA). Cells were harvested and lysed $48 \mathrm{~h}$ later for detecting the luciferase activity using Dual-Luciferase Assay system (Promega, USA).

Flow cytometry. Cells were harvested and fixed by cold $70 \%$ alcohol on ice for $2 \mathrm{~h}$. Then the cells were washed with PBS and treated with RNase A $(10 \mathrm{mg} / \mathrm{ml})$. Propidium iodide (PI) staining solution (40 mg/ml) was added for $15 \mathrm{~min}$ incubation. Cell cycles were analyzed by Cytomics FC 500 instrument (Beckman Coulter).

Statistical analysis. Experiments were performed at least 3 times independently unless otherwise stated. Data statistical significance was determined between groups by Student's t-test or one-way Anova. Values were presented as the mean $\pm \mathrm{SD} .{ }^{*},{ }^{* *},{ }^{* *}$ represent $\mathrm{p}<0.05, \mathrm{p}<0.01, \mathrm{p}<0.001$, respectively.

\section{Results}

miR-342-3p and miR-377 repressed the proliferation of glioma cells. We performed the MTS proliferation assay and found out that transfection with miR-342-3p and miR-377 mimics for overexpression significantly repressed the proliferation capability of U251 (Figure 1A) and U87 cells (Suppl. Figure S1A). The amounts of U251 cells transfected with miR-342-3p and miR-377 respectively were lower than control groups (Figure 1B). We further detected an increase of G1 phase cell proportion and decrease of cells in $\mathrm{S}$, and G2/M phase proportion in U251 cells overexpressing miR-342-3p and miR-377 mimics, respectively (Figure 1C, Figure S1C). CCND1, CCNE1, cell cycle related genes, were downregulated. Cyclin-dependent kinase inhibitor $1 \mathrm{~A}$ (p21) and cyclin-dependent kinase inhibitor 1B (p27) were upregulated in the U251 cells overexpressing miR-342-3p or miR-377 (Figure 1D). On the contrary, we found that transfection with the antisense of miR-342-3p or miR-377, miRNA inhibitor which combines with miRNAs to prevent miRNA- 
A

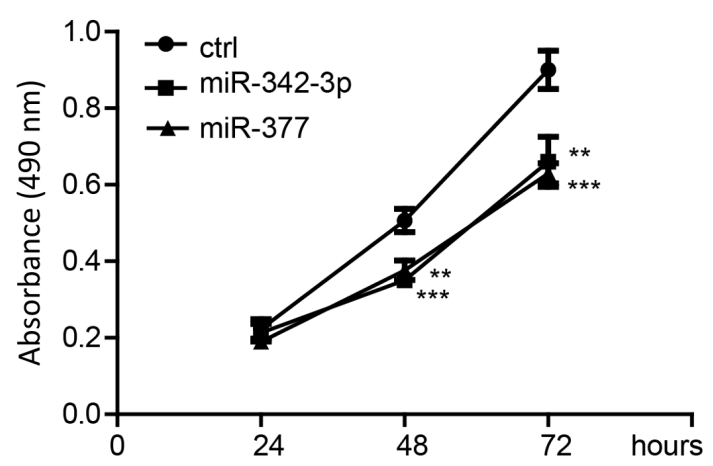

C

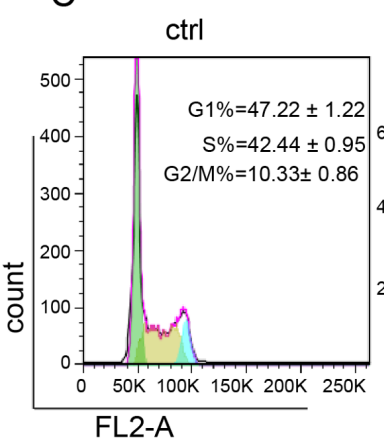

E

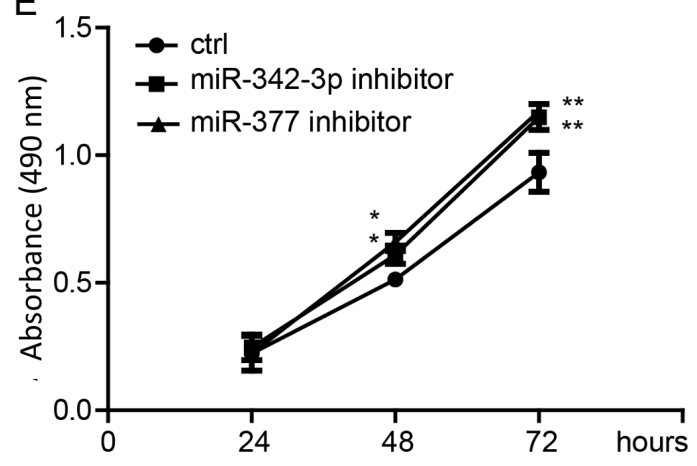

G

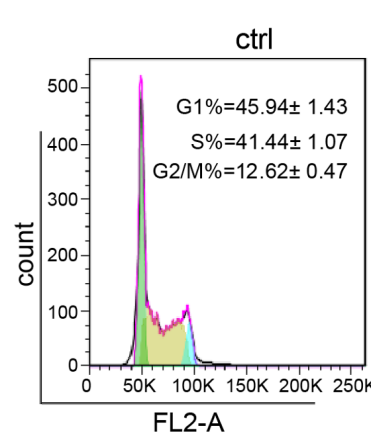

B

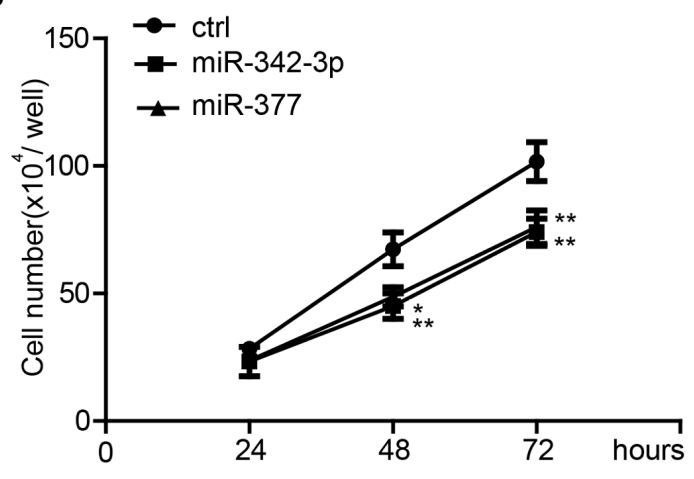

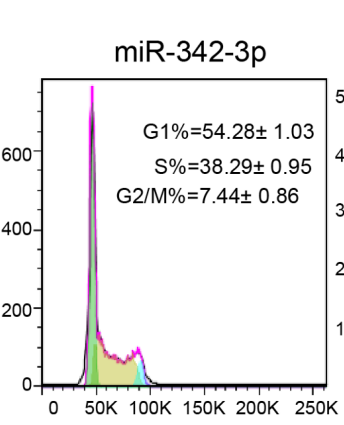
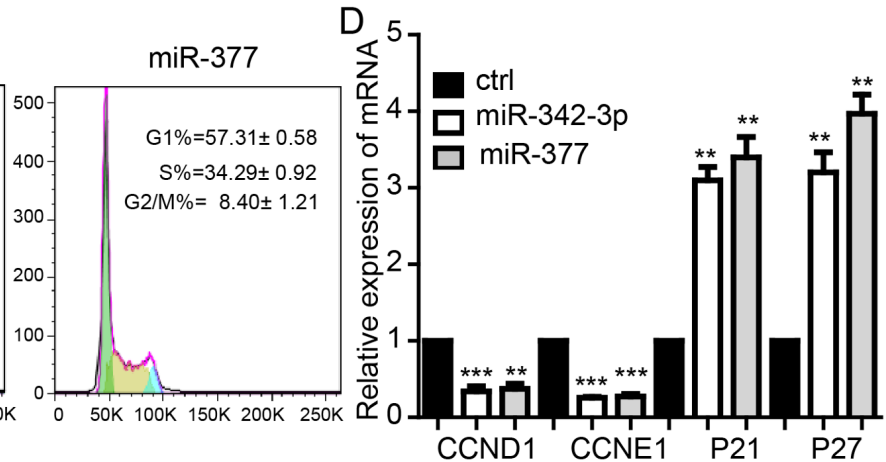

F

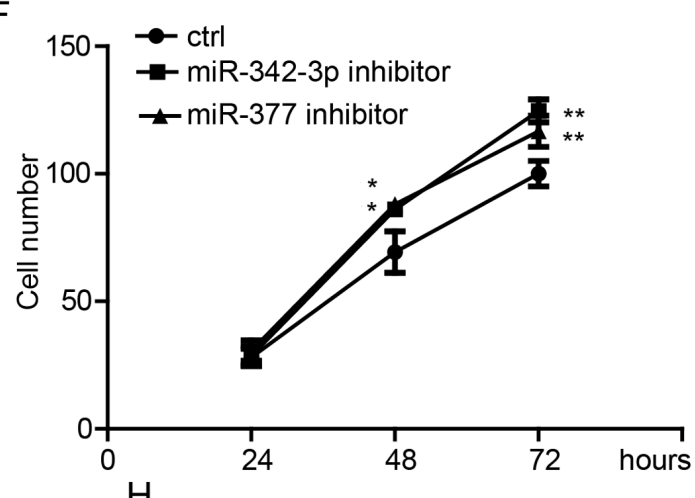

$\mathrm{H}$

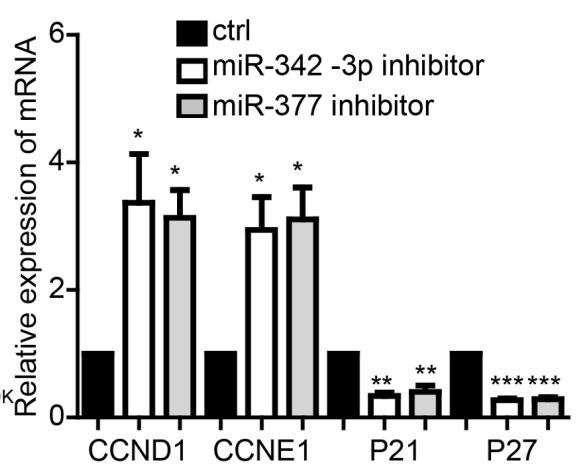

Figure 1 miR-342-3p and miR-377 repressed the cell proliferation of glioma cell line U251. A) miR-342-3p and miR-377 repress the cell proliferation detected by MTS assay during 24, 48, $72 \mathrm{~h}$ in U251 cells. Data $(\mathrm{n}=5)$ shown are means \pm SD. B) Counting of the U251 cell numbers transfected with miR342-3p or miR-377 during 24, 48, $72 \mathrm{~h}$. C) Flow cytometry assay detection indicated the G1 phase arrest via overexpressing miR-342-3p or miR-377. D) miR-342-3p and miR-377 regulated the cell cycle related genes expression. Data $(n=5)$ shown are means \pm SD. E) Transfection of miR-342-3p or miR377 inhibitor promoted the cell proliferation detected by MTS assay. F) Total cell counts were increased by transfecting miRNA inhibitor in U251cells. G) Flow cytometry assay detection of cells transfected with miR-342-3p or miR-377 inhibitor. H) miR-342-3p or miR-377 inhibitor increased the expression of CCND1 and CCNE1 and decreased the p21 and p27. Data shown are means \pm SD $(n=5)$. 
mRNA 3'UTR combination, into U251 (Figure 1E) and U87 cells (Suppl. Figure 1B) significantly promoted the cell proliferation. The total amounts of cells were also increased (Figure 1F). There was a decrease of G1 phase proportion and increase of S, G2/M phases in U251 cells transfected with miR-342-3p and miR-377 inhibitor, respectively (Figure 1G, Suppl. Figure S1D). CCND1, CCNE1 were upregulated and p21, p27 were downregulated in the U251 cells transfected with miR-342-3p or miR-377 inhibitor (Figure $1 \mathrm{H}$ ).

miR-342-3p or miR-377 targeted the E2F1 to repress the expression. Online bioinformatics tool Miranda showed the targeting sites of E2F1 3'UTR combined with miR-342-3p and miR-377 (Figure 2A). The overexpression of miR-342-3p and $\mathrm{miR}-377$ inhibited the luciferase activities of the wild type E2F1 3 'UTR reporter respectively, but could not regulate the expression of mutant UTR reporter without miRNA-binding site sequences (Figure 2B). We further proved that overexpression of miR342-3p and miR-377 repressed the level of E2F1 mRNA (Figure 2C) and the expression of protein (Figure 2D).

Downregulation of E2F1 inhibited the glioma cell proliferation. We downregulated the E2F1 expression by transfecting E2F1 siRNA (Figure 3A) and found that both U251 (Figure 3B) and U87 (Suppl. Figure S2A) cell proliferation was inhibited by E2F1 knockdown. Cell counting also confirmed the decrease of U251 cell numbers caused by E2F1 knockdown (Figure 3C). We also detected that there was an increase of G1 phase proportion and decrease of S, G2/M phase in U251 cells with E2F1 downregulation (Figure 3D, Suppl. Figure S2B). Knockdown of E2F1 also induced the downregulation of CCND1, CCNE1 and upregulation of p21 and p27 in U251 cells (Figure 3E).

E2F1 mediated the function of miR-342-3p and miR-377 in regulation the glioma cell proliferation. We performed the rescue experiment with the co-overexpression of the E2F1 and miR-342-3p (Figure 4A) and detected that overexpression of E2F1 in both U251 (Figure 4B) and U87 cells (Suppl. Figure S3A) could block the proliferation repression caused by miR-342-3p overexpression. Cell counting also showed that E2F1 overexpression rescued the inhibition of miR-342-3p on cell proliferation (Figure 4C). The cell cycle arrest caused by overexpression of miR-342-3p could also be rescued by overexpression of E2F1 (Figure 4D, Suppl. Figure S3C). The expression of cell cycle related genes CCND1, CCNE1, p21, p27 were also restored by E2F1 in U251 cells overexpressing miRNAs (Figure 4E). We also overexpressed the E2F1 in cells that also were transfected with miR-377 for rescue experiment (Figure 4F) and found that E2F1 restored the proliferation capability that was repressed by miR-377 (Figure 4G, Figure 4H, Suppl. Figure S3B). Overexpression of E2F1 could rescue the cell arrest and influence the expression of cell cycle related genes expression caused by miR-377 (Figure 4I, Suppl. Figure S3D, Figure 4J).
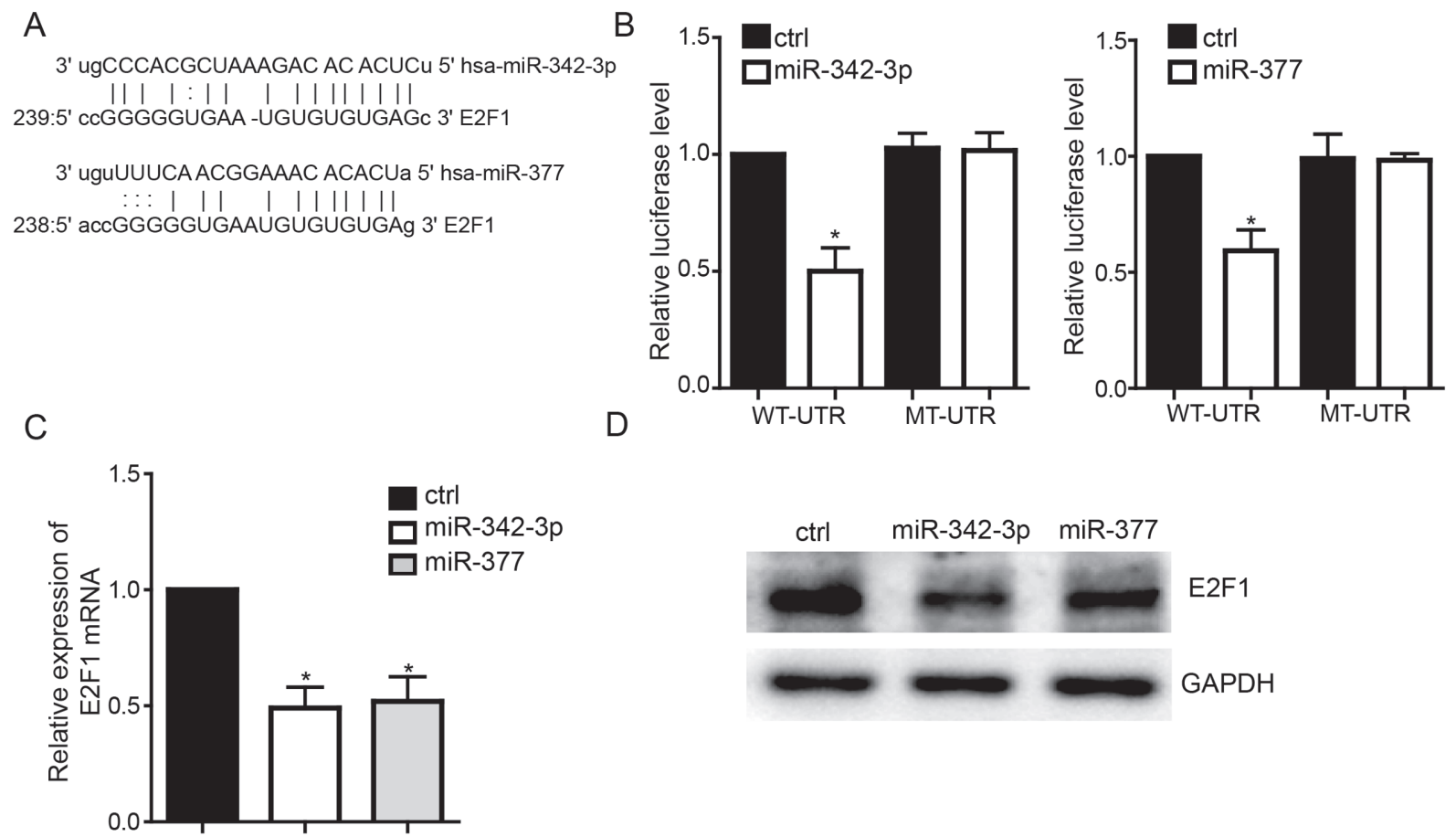

Figure 2. miR-342-3p or miR-377 targeted the E2F1 to repress the expression. A) E2F1 3'UTR target validation of miR-342-3p and miR-377. B) Luciferase reporter assays indicated the binding of miR-342-3p or miR-377 on E2F1 3'UTR. Data ( $n=5)$ shown are means \pm SD. C) Downregulation of E2F1 level detected by qRT-PCR in U251 cells transfected with miR-342-3p or miR-377. D) Represent picture shows the repression of E2F1 expression by miRNAs detected by western blot. 
A
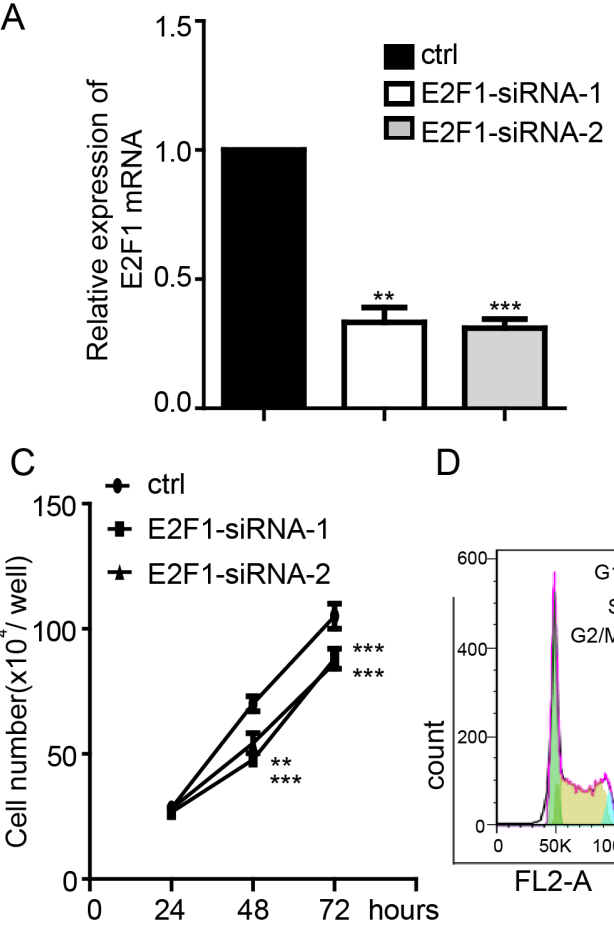

D
B

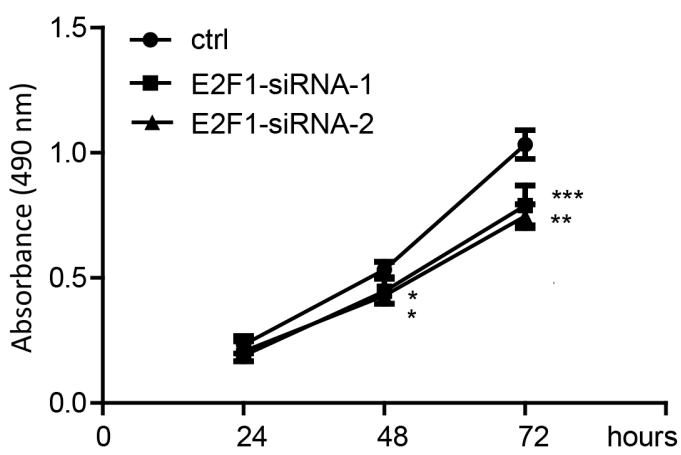

$\mathrm{E}$
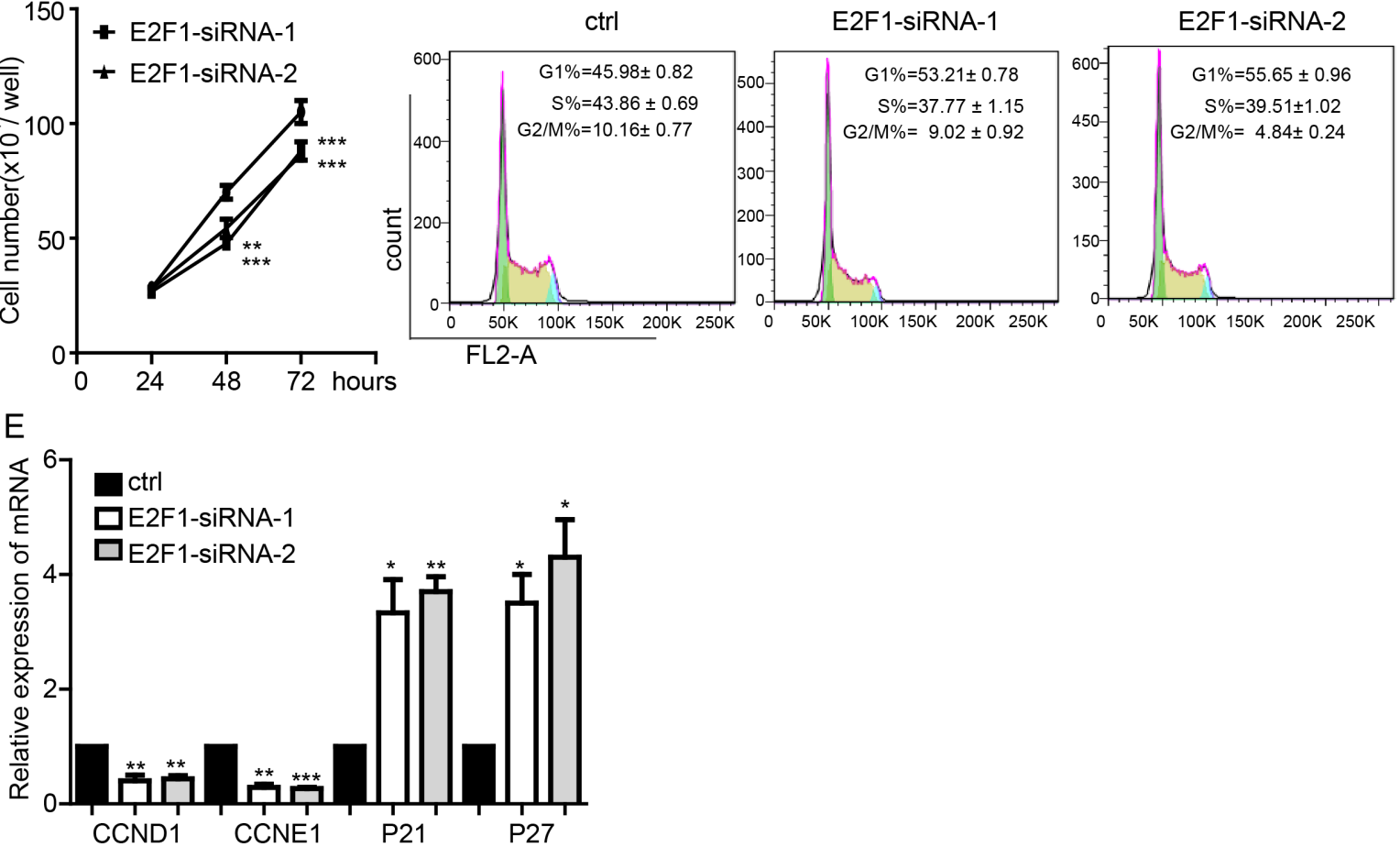

Figure 3 Downregulation of E2F1 inhibited the glioma cell proliferation. A) Downregulation of expression of E2F1 by siRNA. B) Knockdown of E2F1 repressed the cell proliferation. C) Total cell counts were decreased by downregulating of E2F1 expression in U251 cells. D) Flow cytometry analysis indicated that downregulation of E2F1 induced the G1 phase arresting. E) Downregulation of E2F1 influenced the cell cycle related genes expression.

\section{Discussion}

Rapid proliferation of glioma cells, which ensures the subsequent invasion and migration, has become one of the great challenges of clinical treatment [23]. Investigation of glioma proliferation molecular signaling pathway is of great importance in order to develop new diagnostic markers and therapeutic targets $[24,25]$.

MicroRNAs have been reported to be the critical regulators in cancer cells proliferation. miR-429 suppresses the glioblastoma multiforme cell proliferation by directly targeting SOX2 [26]. Repression of miR-155 in glioma cells inhibited the proliferation [27]. miR-592 targeted the IGFBP2 to be a tumor suppressor in glioma [28]. miR-202 inhibits cell proliferation by targeting metadherin [29]. These studies showed that miRNAs play important roles as the key switch to regulate glioma proliferation by targeting downstream cancer related regulators. In this study, we also detected that both miR-342-3p and miR-377 could inhibit glioma cells proliferation. These two miRNAs induced the cell cycle arrest at G1 phase. Additionally, inhibition of the function of miR-342-3p and miR-377 promoted cell proliferation and decreased the proportion of cells in G1 phase, inducing more cells into the cell division cycle of G2/M phase. Our study indicated the function of miR-342-3p and miR-377 in the induction of cell cycle arrest thus inhibiting the cell proliferation, which suggested that the two miRNAs might be the potential clinical treatment targets. 

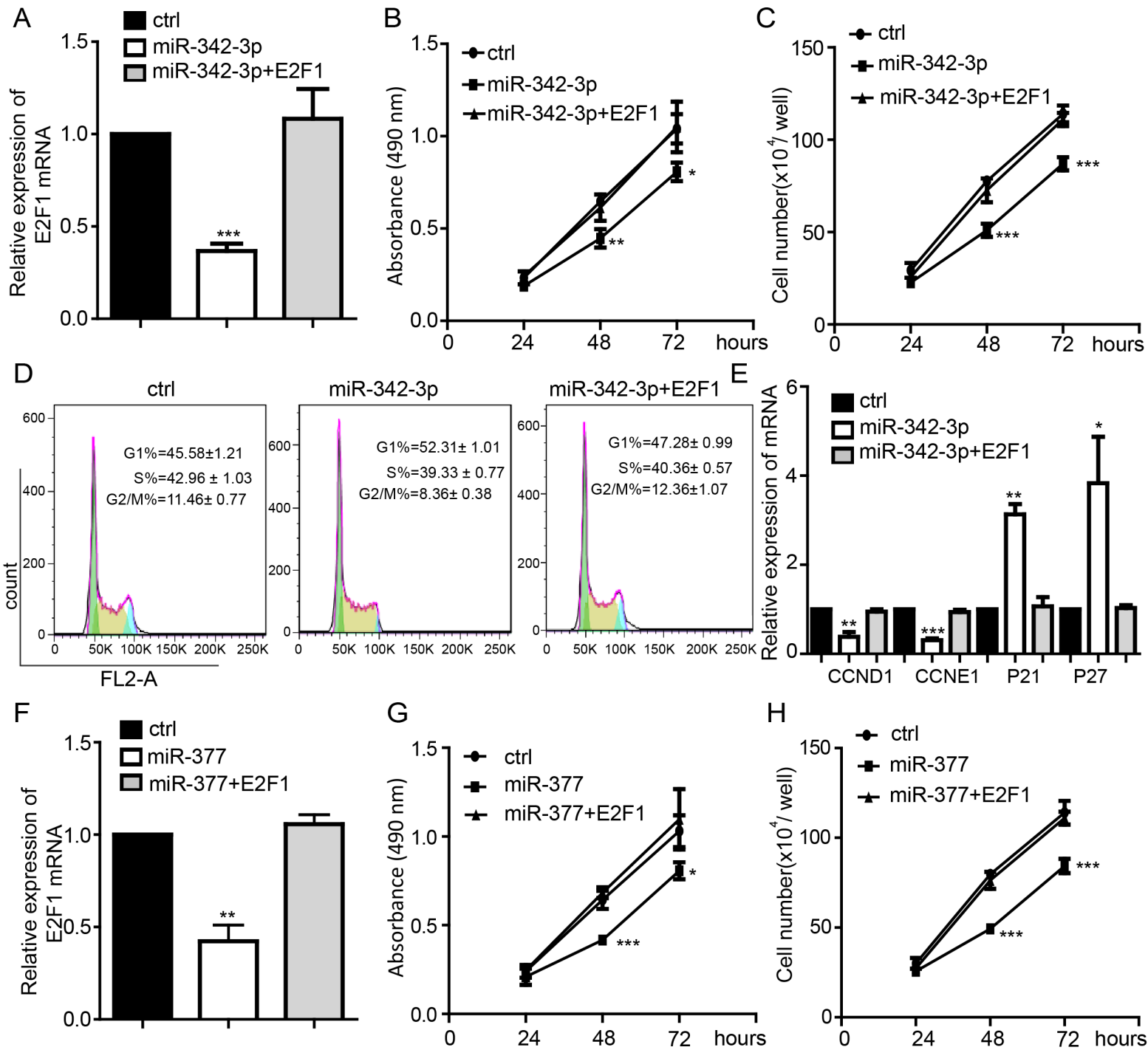

I
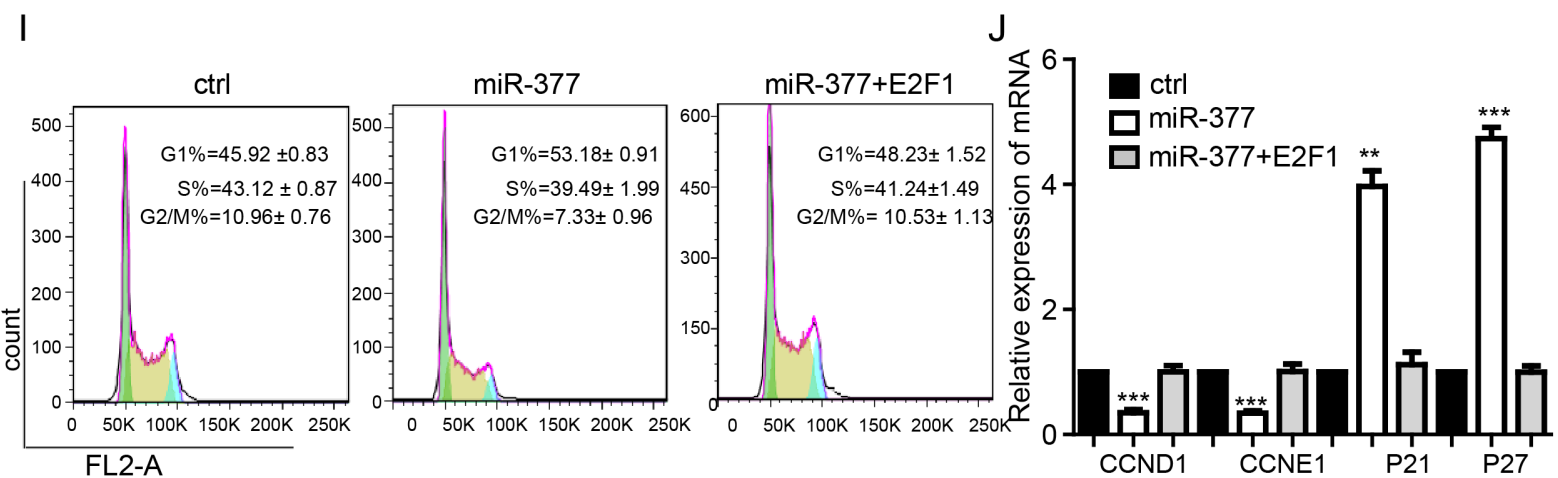

Figure 4. E2F1 mediated the function of miR-342-3p and miR-377 on regulating the glioma cell proliferation. A) Detection of the expression of E2F1 in the U251 cells co-overexpressed with E2F1 and miR-342-3p compared with control group. Data shown are means \pm SD $(n=5)$. B) Overexpression of E2F1 restored the proliferation repressed by miR-342-3p. Data shown are means \pm SD $(n=4)$. C) Total cell counting showed the overexpression of E2F1 rescue the inhibition of miR-342-3p. D) Overexpression of E2F1 rescued the G1 phase arresting caused by miR-342-3p. Data shown are means \pm SD (n=5). E) E2F1 restored the regulation of cell cycle related genes expression. F) Overexpression of E2F1 in the U251 cells transfected with miR-377. Data shown are means \pm SD $(n=5)$. G) E2F1 restored the proliferation repression caused by miR-377. Data shown are means \pm SD $(n=4)$. $H)$ Overexpression of E2F1 restored the inhibition of miR-377. I) E2F1 restored the cell cycle regulation influenced by miR-377. J) E2F1 rescued the cell cycle related genes expression regulated by miR-377. 
Many critical cancer-related genes were regulated by miRNAs. miR-374c-5p targets Foxc1/Snail pathway to regulate the invasion of cervical cancer cell [30]. miR-503-3p induces apoptosis by targeting p21 and CDK4 of lung cancer cells [31]. miR-155 directly targets PDCD4 to inhibit proliferation of lung cancer [32]. Activation of E2F1 by DEPDC1 promotes cell proliferation in prostate cancer cells [33]. E2F1also mediated the function of Klf4 on promoting melanoma cell growth [34]. In our study we detected that E2F1 expression was repressed by miR-342-3p and miR-377. Knockdown of E2F1 inhibited the proliferation of glioma cells and arrested the cell cycle at G1 phase, which was similar with the function of miR-342-3p or miR-377overexpression. Both miR-342-3p and miR-377 directly targeted the E2F1. In general, miRNA can repress multiple target genes and one gene can be repressed by multiple miRNAs to form the complex regulatory networks [35]. Previous study showed that miR-342-3p and miR-205-5p work together to repress E2F1 to be the anticancer regulators in human non-small cell lung carcinoma cell line [36]. This study suggested the complex regulation of E2F1 expression by miRNAs and this regulatory pathway maybe participates also in the glioma cell proliferation, which remains for further investigation. In our study, overexpression of E2F1 restored the cell proliferation and cell cycle regulation that was inhibited by overexpression of miR-342-3p or miR-377. These results indicated that E2F1 is the critical modulator mediated by the miR-342-3p and miR-377 function. The glioma cell proliferation can be regulated by miR-342-3p and miR-377/ E2F1signaling axis. Our work suggested that miR-342-3p and miR-377/ E2F1 could also be therapeutic target or diagnostic marker for future clinical treatment.

Supplementary information is available in the online version of the paper.

\section{References}

[1] WEN PY, KESARI S. Malignant gliomas in adults. N Engl J Med 2008; 359: 492-507. https://doi.org/10.1056/NEJMra0708126

[2] CHEN R, NISHIMURA MC, BUMBACA SM, KHARBANDA S, FORREST WF et al. A hierarchy of self-renewing tumor-initiating cell types in glioblastoma. Cancer Cell 2010; 17: 362-375. https://doi.org/10.1016/j.ccr.2009.12.049

[3] LI C, LEI B, HUANG S, ZHENG M, LIU Z et al. H19 derived microRNA-675 regulates cell proliferation and migration through CDK6 in glioma. Am J Transl Res 2015; 7: 1747-1764.

[4] THORNE AH, ZANCA C, FURNARI F. Epidermal growth factor receptor targeting and challenges in glioblastoma. Neuro Oncol 2016; 18, 914-918. https://doi.org/10.1093/ neuonc/nov319
[5] CAHILL KE, MORSHED RA, YAMINI B. Nuclear factorkappaB in glioblastoma: insights into regulators and targeted therapy. Neuro Oncol 2016; 18, 329-339. https://doi. org/10.1093/neuonc/nov265

[6] LIU Q, WANG G, CHEN Y, LI G, YANG D et al. A miR-590/ Acvr2a/Rad51b axis regulates DNA damage repair during mESC proliferation. Stem Cell Reports 2014; 3: 1103-1117. https://doi.org/10.1016/j.stemcr.2014.10.006

[7] XI J, WU Y, LI G, MA L, FENG K et al. Mir-29b Mediates the Neural Tube versus Neural Crest Fate Decision during Embryonic Stem Cell Neural Differentiation. Stem Cell Reports 2017; 9: 571-586. https://doi.org/10.1016/j.stemcr.2017.06.017

[8] SETIEN-OLARRA A, GAINZA-CIRAUQUI ML, AGUIRRE-URIZAR JM, MARICHALAR-MENDIA X. The role of microRNAs in oral lichenoid disorders. Med Oral Patol Oral Cir Bucal 2017; 22: e548-e553. https://doi.org/10.4317/ medoral.21819

[9] CHEN JJ, ZHAO B, ZHAO J, LI S. Potential Roles of Exosomal MicroRNAs as Diagnostic Biomarkers and Therapeutic Application in Alzheimer's Disease. Neural Plast 2017; 2017: 7027380. https://doi.org/10.1155/2017/7027380

[10] GAN L, DENECKE B. Co-regulation of microRNAs and transcription factors in cardiomyocyte specific differentiation of murine embryonic stem cells: An aspect from transcriptome analysis. Biochim Biophys Acta Gene Regul Mech 2017; 1860: 983-1001. https://doi.org/10.1016/j. bbagrm.2017.07.009

[11] WANG D, REN J, REN H, FU JL, YU D. MicroRNA-132 suppresses cell proliferation in human breast cancer by directly targeting FOXA1. Acta Pharmacol Sin 2018; 39: 124131. https://doi.org/10.1038/aps.2017.89

[12] WANG Z, ZHENG C, JIANG K, HE J, CAO X et al. MicroRNA-503 suppresses cell proliferation and invasion in osteosarcoma via targeting insulin-like growth factor 1 receptor. Exp Ther Med 2017; 14: 1547-1553. https://doi.org/10.3892/ etm.2017.4648

[13] YU J, WU SW, WU WP. A tumor-suppressive microRNA, miRNA-485-5p, inhibits glioma cell proliferation and invasion by down-regulating TPD52L2. Am J Transl Res 2017; 9: 3336-3344.

[14] RASTOGI B, KUMAR A, RAUT SK, PANDA NK, RATTAN V et al. Downregulation of miR-377 Promotes Oral Squamous Cell Carcinoma Growth and Migration by Targeting HDAC9. Cancer Invest 2017; 35: 152-162. https://doi. org/10.1080/07357907.2017.1286669

[15] CHANG W, LIU M, XU J, FU H, ZHOU B et al. MiR-377 inhibits the proliferation of pancreatic cancer by targeting Pim-3. Tumour Biol 2016; 37: 14813-14824. https://doi. org/10.1007/s13277-016-5295-4

[16] ZHAO JY, WANG F, LI Y, ZHANG XB, YANG L et al. Five miRNAs Considered as Molecular Targets for Predicting Esophageal Cancer. Med Sci Monit 2015; 21: 3222-3230.

[17] HALLSTROM TC, MORI S, NEVINS JR. An E2F1-dependent gene expression program that determines the balance between proliferation and cell death. Cancer Cell 2008; 13: 11-22. https://doi.org/10.1016/j.ccr.2007.11.031 
[18] DEGREGORI J, LEONE G, MIRON A, JAKOI L, NEVINS JR. Distinct roles for E2F proteins in cell growth control and apoptosis. Proc Natl Acad Sci U S A 1997; 94: 7245-7250.

[19] ZHANG X, LIU G, QIU J, ZHANG N, DING J et al. E2F1regulated long non-coding RNA RAD51-AS1 promotes cell cycle progression, inhibits apoptosis and predicts poor prognosis in epithelial ovarian cancer. Sci Rep 2017; 7: 4469. https://doi.org/10.1038/s41598-017-04736-z

[20] YIN J, FU W, DAI L, JIANG Z, LIAO H et al. ANKRD22 promotes progression of non-small cell lung cancer through transcriptional up-regulation of E2F1. Sci Rep 2017; 7: 4430. https://doi.org/10.1038/s41598-017-04818-y

[21] SUN JY, XIAO WZ, WANG F, WANG YQ, ZHU YH et al. MicroRNA-320 inhibits cell proliferation in glioma by targeting E2F1. Mol Med Rep 2015; 12: 2355-2359. https://doi. org/10.3892/mmr.2015.3657

[22] HUANG Y, HONG X, HU J, LU Q. Targeted regulation of MiR-98 on E2F1 increases chemosensitivity of leukemia cells K562/A02. Onco Targets Ther 2017; 10: 3233-3239. https:// doi.org/10.2147/OTT.S126819

[23] WU M, WANGGOU S, LI X, LIU Q, XIE Y. Overexpression of mitochondrial serine hydroxyl-methyltransferase 2 is associated with poor prognosis and promotes cell proliferation and invasion in gliomas. Onco Targets Ther 2017; 10: 3781-3788. https://doi.org/10.2147/OTT.S130409

[24] VIGNESWARAN K, NEILL S, HADJIPANAYIS CG. Beyond the World Health Organization grading of infiltrating gliomas: advances in the molecular genetics of glioma classification. Ann Transl Med 2015; 3: 95. https://doi. org/10.3978/j.issn.2305-5839.2015.03.57

[25] WANG Y, JIANG T. Understanding high grade glioma: molecular mechanism, therapy and comprehensive management. Cancer Lett 2013; 331: 139-146. https://doi. org/10.1016/j.canlet.2012.12.024

[26] DONG H, HAO X, CUI B, GUO M. MiR-429 suppresses glioblastoma multiforme by targeting SOX2. Cell Biochem Funct 2017; 35: 260-268. https://doi.org/10.1002/cbf.3271

[27] GU J, LU Z, JI C, CHEN Y, LIU Y et al. Melatonin inhibits proliferation and invasion via repression of miRNA-155 in glioma cells. Biomed Pharmacother 2017; 93: 969-975. https://doi.org/10.1016/j.biopha.2017.07.010
[28] PENG T, ZHOU L, QI H, WANG G, LUAN Y et al. MiR592 functions as a tumor suppressor in glioma by targeting IGFBP2. Tumour Biol 2017; 39: 1010428317719273. https:// doi.org/10.1177/1010428317719273

[29] YANG J, FAN B, ZHAO Y, FANG J. MicroRNA-202 inhibits cell proliferation, migration and invasion of glioma by directly targeting metadherin. Oncol Rep 2017; 38: 1670-1678. https://doi.org/10.3892/or.2017.5815

[30] BYRNE EJ, LOWE J, GODWIN-AUSTEN RB, ARIE T, JONES R. Dementia and Parkinson's disease associated with diffuse cortical Lewy bodies. Lancet 1987; 1: 501. https://doi. org/10.1016/S0140-6736(87)92104-0

[31] SUN Y, LI L, XING S, PAN Y, SHI Y et al. miR-503-3p induces apoptosis of lung cancer cells by regulating p21 and CDK4 expression. Cancer Biomark 2017; 20: 597-608. https://doi. org/10.3233/CBM-170585

[32] LIU F, SONG D, WU Y, LIU X, ZHU J et al. MiR-155 inhibits proliferation and invasion by directly targeting PDCD4 in non-small cell lung cancer. Thorac Cancer 2017; 8: 613-619. https://doi.org/10.1111/1759-7714.12492

[33] HUANG L, CHEN K, CAI ZP, CHEN FC, SHEN HY et al. DEPDC1 promotes cell proliferation and tumor growth via activation of E2F signaling in prostate cancer. Biochem Biophys Res Commun 2017; 490: 707-712. https://doi. org/10.1016/j.bbrc.2017.06.105

[34] RIVERSO M, MONTAGNANI V, STECCA B. KLF4 is regulated by RAS/RAF/MEK/ERK signaling through E2F1 and promotes melanoma cell growth. Oncogene 2017; 36: 33223333. https://doi.org/10.1038/onc.2016.481

[35] XU N, PAPAGIANNAKOPOULOS T, PAN G, THOMSON JA, KOSIK KS. MicroRNA-145 regulates OCT4, SOX2, and KLF4 and represses pluripotency in human embryonic stem cells. Cell 2009; 137: 647-658. https://doi: 10.1016/j. cell.2009.02.038

[36] LAI X, GUPTA SK, SCHMITZ U, MARQUARDT S, KNOLL $S$ et al. MiR-205-5p and miR-342-3p cooperate in the repression of the E2F1 transcription factor in the context of anticancer chemotherapy resistance. Theranostics 2018; 8: 1106-1120. https://doi.org/10.7150/thno.19904 